Reviu Akuntansi dan Bisnis Indonesia, Vol. 3 No. 1, Hlm: 38-49, Juli 2019

Website: http://journal.umy.ac.id/index.php/rab

\title{
Pengaruh Intellectual Capital, Efisiensi Operasional, dan Islamicity Performance Index, Terhadap Profitabilitas Bank Syariah di Indonesia
}

\author{
Yiyi Dian Dwi Putri; Barbara Gunawan* \\ Program Studi Akuntansi Universitas Muhammadiyah Yogyakarta \\ I N F O A R T IKEL \\ Kata Kunci: \\ Intellectual Capital, \\ Operational Efficiency, and \\ Islamicity Performance \\ Index. \\ Jenis Artikel: \\ Penelitian Empiris \\ *Correspondence: \\ era@umy.ac.id

\begin{abstract}
A B S T R A K
This study aims to analyze the influence of intellectual capital, operational efficiency, and islamicity performance index in the profitability of Indonesian Sharia Banks. The object in this study was all of sharia banks in Indonesia that registered at Otoritas Jasa Keuangan (OJK). In this study, 6 sharia banks with research period since 2012 until 2017 were selected using purposive sampling. Analysis tool used in this study is the SPSS.

Based on the analysis that have been made the results are the intellectual capital does not influence profitability, the low level of operational efficiency has a negative influence on profitability, and islamicity performance index significantly influence the profitability.
\end{abstract}

(C) 2019 RAB. Published by Universitas Muhammadiyah Yogyakarta

\section{PENDAHULUAN}

Industri perbankan syariah berkembang begitu pesat di Indonesia. Hal ini dapat disebabkan oleh banyaknya pemeluk agama Islam di Indonesia sehingga memungkinkan angka minat masyarakat untuk menggunakan layanan perbankan syariah menjadi tinggi. Perkembangan industri perbankan syariah juga dibuktikan secara statistik oleh Otoritas Jasa Keuangan (2017) yaitu dengan terus meningkatnya jumlah aset Bank Umum Syariah dari tahun ke tahun. Hal ini tentu menjadi pembuka jalan yang baik untuk mewujudkan salah satu visi yang ditetapkan oleh Bank Indonesia, yaitu menjadikan perbankan syariah Indonesia menjadi terkemuka di ASEAN (Awwalin, 2015). Untuk menindaklanjuti visi tersebut, sudah semestinya perkembangan perbankan syariah ini diikuti dengan efisiensi pengelolaan aset dan sumber daya lain agar perbankan syariah dapat memperoleh keuntungan yang optimal.

Namun, pada kenyataannya peningkatan aset bank syariah tersebut tidak selalu sejalan dengan efisiensi bank syariah dalam menjalankan roda perusahaannya. Hal ini ditunjukkan oleh data statistik perbankan syariah yang dilaporkan oleh Otoritas Jasa Keuangan (2017). Data menunjukkan bahwa masih terjadi fluktuasi pendapatan dan laba pada bank syariah selama enam tahun terakhir.

Informasi fluktuasi pendapatan dan laba bank syariah menunjukkan bahwa masih terjadi kurangnya efisiensi di bank syariah karena peningkatan laba belum dapat menyamai besarnya persentase peningkatan pendapatan bahkan di beberapa tahun peningkatan pendapatan justru diikuti dengan turunnya laba yang dihasilkan perbankan syariah. Untuk mewujudkan visi Bank Indonesia agar bank syariah Indonesia dapat menjadi terkemuka di ASEAN, perlu dilakukan perbaikan dan upaya peningkatan kinerja perbankan syariah. Penting bagi perbankan syariah untuk mengetahui aspek apa saja yang dapat memengaruhi tingkat profitabilitasnya agar pihak yang 
berwenang dapat mengambil keputusan yang tepat sasaran dalam menjalankan upaya untuk meningkatkan profitabilitas perbankan syariah.

Untuk meningkatkan aspek kinerja, sumber daya insani (SDI) yang memiliki pemahaman mengenai ekonomi syariah dan dapat menerapkan pemahaman tersebut tentu sangat diperlukan di sektor perbankan syariah sehingga kinerja perbankan syariah diharapkan dapat semakin meningkat. Sehingga intellectual capital menjadi sangat penting untuk meningkatkan kinerja dan nilai perusahaan sebagaimana dalam penelitian Sari dan Gunawan (2011) yang menyatakan bahwa suatu perusahaan yang mampu mengelola intellectual capital secara optimal maka akan mengakibatkan nilai tambah yang akan berpengaruh terhadap kinerja keuangannya. Penelitian mengenai keterkaitan antara intellectual capital dengan profitabilitas perusahaan dilakukan oleh Ousama dan Fatima (2015), dan Umami (2017) menghasilkan bukti empiris bahwa intellectual capital berpengaruh positif terhadap profitabilitas peruasahaan. Namun, penelitian yang dilakukan oleh Pal dan Soriya (2012) serta Rosafitri (2017) menunjukkan hasil bahwa intellectual capital tidak berpengaruh secara signifikan terhadap profitabilitas perusahaan. Terjadinya inkonsistensi ini mendorong penulis untuk meneliti pengaruh intellectual capital terhadap profitabilitas perbankan syariah.

Selain intellectual capital, salah satu aspek yang tidak dapat diabaikan adalah efisiensi operasional. Semakin efisien suatu bank dalam mengelola sumber daya dan melakukan kegiatan operasionalnya, maka diharapkan profitabilitas yang dihasilkan menjadi semakin tinggi. Rasio Biaya Operasional per Pendapatan Operasional (BOPO) digunakan sebagai alat ukur variabel efisiensi operasional dapam penelitian ini. Semakin kecil nilai rasio ini, menunjukkan bahwa kinerja perbankan tersebut semakin efisien.

Penelitian mengenai BOPO sudah beberapa kali dilakukan, akan tetapi masih terjadi inkonsistensi hasil sebagaimana ditunjukkan dari hasil penelitian yang dilakukan oleh Prasetyo dan Darmayanti (2015), Wibowo dan Syaichu (2016), serta penelitian Hakiim dan Rafsanjani (2016) yang menyatakan bahwa efisiensi operasional yang diukur dengan BOPO berpengaruh negatif terhadap profitabilitas. Sedangkan sebaliknya, hasil dari penelitian Parawouw (2014) menyatakan bahwa BOPO justru berpengaruh signifikan positif terhadap profitabilitas.

Selain itu, upaya peningkatan kinerja pebankan syariah juga tidak dapat terlepas dari aspek keislaman yang diterapkan dalam kegiatan di bank syariah. Hameed dkk. (2004) menyajikan alternatif alat ukur yang dapat digunakan untuk mengukur nilai materialistik dan nilai keislaman yang seharusnya dimiliki bank syariah. Alat ukur ini disebut dengan Islamicity Performances Index. Islamicity Performances Index memiliki tujuh rasio, yaitu profit sharing ratio (PSR), zakat performances ratio (ZPR), equitable distribution ratio (EDR), directors-employee's welfare ratio, Islamic investment vs non-Islamic investment, islamic income and non-islamic income, serta AAOIFI index. Ketaatan dalam menjalankan roda perusahaan sesuai dengan syariah Islam ini memungkinkan meningkatnya kepercayaan calon pengguna produk di perbankan syariah sehingga dapat meningkatkan profitabilitas bank syariah. Berangkat dari penjelasan tersebut, penulis tertarik untuk meneliti mengenai pengaruh Islamicity Performances Index terhadap profitabilitas perbankan syariah.

\section{TINJAUAN LITERATUR DAN PERUMUSAN HIPOTESIS}

\section{Resources Based Theory}

Sumber daya yang dimiliki oleh suatu entitas besifat heterogen satu sama lain. Sumber daya tersebut dapat menjadi keunggulan kompetitif suatu entitas apabila entitas tersebut dapat memperoleh, mempertahankan, dan mengelolanya. Resources Based Theory ini dikembangkan oleh Barney (1991) dan teori ini memiliki asumsi bahwa suatu entitas dikatakan berhasil apabila sumber daya menjadi keunggulan kompetitif ini akan menciptakan nilai tambah yang tidak mudah ditiru oleh entitas lain. 


\section{Sharia Enterprise Theory}

Menurut Andriana dkk. (2017), Sharia Enterprise Theory menyatakan bahwa tanggung jawab sebuah entitas bukan hanya kepada pemilik perusahaan tersebut melainkan kepada kelompok stakeholder yang lebih luas. Stakeholder dalam teori ini merupakan Allah, manusia, dan alam. Allah merupakan pemegang kekuasaan tertinggi, sehingga akuntansi syariah dibuat dan dijalankan berdasarkan aturan-aturan Allah. Teori ini tidak menjadikan manusia sebagai pusat atas kepentingan dalam menjalankan sebuah entitas. Allah yang menjadi pusat kepentingan atas proses berjalannya entitas ini.

\section{Intellectual Capital}

Menurut Ghosh dan Mondal (2012) intellectual capital merupakan atribut organisasi yang mengambil peran penting untuk meningkatkan keunggulan kompetitif mengingat ketatnya persaingan di berbagai industri. Keunggulan kompetitif serta nilai tambah bagi pihak-pihak yang berkepentingan ini dapat diberikan oleh kualitas yang baik dari intellectual capital. Intellectual capital merupakan aset tidak berwujud.

\section{Biaya Operasional per Pendapatan Operasional (BOPO)}

Rasio BOPO merepresentasikan efisiensi kegiatan operasional bank. Semakin kecil nilai rasio BOPO, maka berarti bank tersebut semakin efisien dalam melakukan aktivitas utamanya. Bank dapat dikategorikan sebagai bank yang sehat jika memiliki rasio BOPO kurang dari satu, sedangkan untuk bank dengan rasio BOPO lebih dari satu menunjukkan bahwa kondisinya tidak sehat (Fadjar dkk., 2017).

\section{Islamicity Performance Index}

Hameed dkk. (2004) menyatakan bahwa ada Islamic Performances Index, yaitu alat pengukuran kinerja yang mampu mengungkapkan nilai-nilai materialistis dan spiritual di Bank Islam.

Penurunan Hipotesis

Intellectual Capital dan Profitabilitas

Sesuai dengan Resources Based Theory yang menyatakan bahwa entitas yang dapat mengelola sumber daya yang dimilikinya dengan baik, maka entitas tersebut akan memiliki keunggulan kompetitif yang tidak mudah ditiru oleh entitas lain. Salah satu sumber daya tersebut adalah sumber daya manusia. Intellectual capital yang baik berpotensi untuk mengelola aset lain dengan baik sehingga dapat meningkatkan laba yang diukur dengan ROA. Maka dari itu, dapat disimpulkan bahwa semakin baik intellectual capital suatu perusahaan maka akan semakin baik pula kinerja yang dapat dihasilkan. Penelitian sebelumnya terkait hubungan antara intellectual capital dengan profitabilitas bank syariah juga pernah dilakukan oleh Ousama dan Fatima (2015), Hasan dkk. (2017) serta Ozkan dkk. (2017) menemukan bukti empiris bahwa intellectual capital berpengaruh positif terhadap profitabilitas bank syariah. Berdasarkan penjelasan tersebut maka ditarik hipotesis:

\section{$\boldsymbol{H}_{\boldsymbol{I}} \quad$ : Intellectual capital berpengaruh positif terhadap profitabilitas bank Syariah}


Efisiensi Operasional dan Profitabilitas

Rasio BOPO menunjukkan biaya yang terjadi untuk setiap rupiah pendapatan yang diperoleh bank. Maka dari itu, dapat disimpulkan bahwa semakin kecil rasio BOPO maka tingkat efisiensi dalam pelaksanaan kegiatan utama bank semakin baik. Semakin kecil biaya yang dikeluarkan tentu akan meningkatkan profitabilitas. Maka dari itu, dapat disimpulkan bahwa rasio BOPO memiliki hubungan yang negatif dengan profitabilitas bank.

Pernyataan tersebut telah dibuktikan secara empiris oleh Prasetyo dan Darmayanti (2015), Harianto (2017), Wibowo dan Syaichu (2013) serta penelitian Hakiim dan Rafsanjani (2016) yang menyatakan bahwa efisiensi operasional yang diukur dengan BOPO berpengaruh negatif terhadap profitabilitas. Berdasarkan penjelasan tersebut maka ditarik hipotesis:

\section{$\boldsymbol{H}_{2} \quad$ : Rendahnya tingkat efisiensi operasional berpengaruh negatif terhadap profitabilitas bank Syariah}

Islamicity Performance Index dan Profitabilitas

Islamicity performance index mengukur kinerja tanpa melupakan kewajiban untuk menjalankan roda lembaga keuangan tersebut sesuai dengan syariat Islam. Sharia enterprise theory yang menyatakan bahwa tanggung jawab dalam menjalankan sebuah entitas bukan hanya kepada pemilik perusahaan tersebut, melainkan kepada kelompok stakeholder yang lebih luas termasuk kepada Allah. Hal ini menunjukkan bahwa dalam menjalankan roda perusahaan, manusia dituntut untuk tetap berada di koridor yang tidak melanggar syariah Islam. Ketaatan terhadap syariah Islam ini dapat meningkatkan kepercayaan calon pengguna produk perbankan syariah sehingga memungkinkan naiknya tingkat profitabilitas bank syariah. Hal ini didukung oleh penelitian yang dilakukan oleh Andraeny dan Putri (2017), Bustmamam dan Aditia (2016), serta Dewanta dkk. (2016) yang berhasil membuktikan secara empiris bahwa islamicity performances index berpengaruh terhadap profitabilitas bank syariah. Berdasarkan penjelasan tersebut maka ditarik hipotesis:

\section{$\boldsymbol{H}_{3} \quad$ : Islamicity performance index berpengaruh positif terhadap profitabilitas bank syariah.}

\section{METODE PENELITIAN}

Obyek, Subyek, Jenis Data, Teknik Pengambilan Sampel dan Teknik Pengambilan Data

Obyek yang digunakan dalam penelitian ini adalah Bank Umum Syariah yang ada di Indonesia. Sedangkan subjek dari penelitian ini adalah laporan keuangan Bank Umum Syariah yang ada di Indonesia mulai tahun 2012 hingga 2017. Penelitian ini merupakan penelitian kuantitatif. Data yang digunakan dalam penelitian ini adalah jenis data sekunder dengan metode dokumentasi yaitu dilakukan dengan mengumpulkan data dari laporan keuangan tahunan masingmasing bank umum syariah. Teknik pengambilan sampel menggunakan teknik purposive sampling dengan ketentuan sebagai berikut:

1. Bank umum syariah di Indonesia terdaftar di OJK

2. Bank umum syariah yang mempublikasikan laporan keuangan tahunan 2012-2017

3. Adanya kelengkapan data yang diperlukan untuk penelitian ini pada periode 2012-2017 
Definisi Operasional Variabel Penelitian

a. Variabel Dependen $(\mathrm{Y})$

Profitabilitas merupakan variabel dependen yang digunakan dalam penelitian ini. Penelitian ini menggunakan ROA sebagai alat ukur profitabilitas. Rasio ini menunjukkan kemampuan bank dalam menghasilkan laba dengan mengelola aset yang dimilikinya.

$$
R O A=\frac{\text { Laba Sebelum Pajak }}{\text { Total Aset }} \times 100 \%
$$

b. Variabel Independen (X)

1) Intellectual Capital

Untuk mengukur kinerja intellectual capital di perbankan syariah, Ulum (2013) sudah mengembangkan alat ukur VAIC agar menjadi lebih relevan untuk digunakan mengukur kinerja intellectual capital pada perbankan syariah yang disebut dengan iB-VAIC. Ada perbedaan yang cukup signifikan dari aspek perhitungan value added (VA) dimana Pulic menyusun perhitungan VA dari total pendapatan, sedangkan Ulum menyusun perhitungan VA dari aktivitas-aktivitas syariah. iB-VAIC terdiri dari tiga elemen utama, yaitu:

a) Value Added Capital Employee (VACA)

$$
i B-V A C A=\frac{\text { Value Added }}{\text { Capital Employee }}
$$

b) Islamic Banking Value Added Human Capital (iB-VAHU)

$$
i B-V A H U=\frac{\text { Value Added }}{\text { Human Capital }}
$$

c) Islamic Banking Structural Capital Value Added (iB-STVA)

$$
i B-S T V A=\frac{\text { Value Added }}{\text { Structural Capital }}
$$

2) Efisiensi Operasional

$$
B O P O=\frac{\text { Biaya Operasional }}{\text { Pendapatan Operasional }}
$$

3) Islamicity Performance Index

Islamicity Performances Index yaitu alat pengukuran kinerja yang mampu mengungkapkan nilai-nilai materialistis dan spiritual di Bank Islam. Berikut merupakan rasio-rasio Islamicity Performances Index yang digunakan dalam penelitian ini:

(a) Profit Sharing Ratio (PSR)

Efisiensi operasional merupakan kemampuan perusahaan dalam mengelola input menjadi output dengan efisien atau secara tepat. Penulis menggunakan rasio BOPO untuk mengukur efisiensi bank. 


\section{Mudharabah + Musyarakah \\ Total Pembiayaan}

(a) Zakat Performance Ratio (ZPR)

$$
\mathrm{ZPR}=\frac{\text { Zakat }}{\text { Net Asset }}
$$

(b) Equitable Distribution Ratio (EDR)

$$
\begin{aligned}
& \frac{\text { Beban Tenaga Kerja }}{\text { Pendapatan }-(\text { zakat }+ \text { pajak })} \\
& \frac{\text { Qard }+ \text { Donasi }}{\text { Pendapatan }-(\text { zakat }+ \text { pajak })}
\end{aligned}
$$

(c) Islamic Income and Non Islamic Income

$$
\frac{\text { Pendapatan halal }}{\text { pendapatan halal }+ \text { pendapatan non halal }}
$$

3. Uji Kualitas Data

a. Uji Statistik Deskriptif merupakan uji yang digunakan untuk menggambarkan dan mendiskripsikan data yang telah dikumpul.

b. Uji Asumsi Klasik

1) Uji Normalitas merupakan pengujian yang berguna untuk menguji apakah residual memiliki distribusi normal menggunakan uji statistik non-parametrik Kolmogorov-Smirnov (KS).

2) Uji Heteroskedastisitas merupakan pengujian untuk mengatahui apakah residual satu pengamatan ke pengamatan lain terdapat ketidaksamaan varians dalam model regresi menggunakan uji glejtzer.

3) Uji Multikolinearitas digunakan untuk mengetahui apakah ditemukan hubungan antar variabel independen dalam model regresi diketahui dengan melihat nilai tolerance dan Variance Inflation Factor (VIF).

4) Uji Autokorelasi bertujuan untuk mengetahui ada atau tidaknya korelasi antara kesalahan pengganggu pada satu periode (t) dengan periode sebelumnya (t-1) (Ghozali, 2011). Pengujian ini mengunakan Durbin-Watson (DW-Test)

4. Uji Hipotesis dan Analisis Data

a. Analisis Regresi

Penelitian ini menggunakan regresi linear berganda untuk mengetahui pengaruh lebih dari satu variabel independen terhadap variabel dependen. Persamaan regresi linear berganda adalah sebagai berikut:

$$
\mathrm{P}=\alpha+\beta_{1} \mathrm{IC}-\beta_{2} \mathrm{EO}+\beta_{3} \mathrm{IPI}+\mathrm{e}
$$


Keterangan :

P : Profitabilitas

$\alpha \quad$ : Konstanta

$\beta 1-\beta 3$ : Koefisien Regresi

IC : Intellectual Capital

EO : Efisiensi Operasional

IPI : Islamicity Performances Index

e : Error Term

b. Uji Koefisien Determinasi (R2)

Uji ini bertujuan untuk mengetahui seberapa besar kemampuan variabel independen dalam menjelaskan variabel dependen.

c. Uji Nilai F

Uji ini merupakan uji yang digunakan untuk mengetahui apakah seluruh variabel independen secara bersama-sama mempunyai pengaruh yang signifikan terhadap variabel dependen.

d. Uji Nilai t

Uji ini digunakan untuk mengetahui secara parsial seberapa jauh pengaruh satu variabel independen terhadap variabel dependen.

\section{HASIL DAN PEMBAHASAN}

1. Statistik Deskriptif

Tabel 1 Statistik Deskriptif

\begin{tabular}{llllll}
\hline & N & Minimum & Maximum & Mean & Std.Deviation \\
\hline ROA & 36 & 0,0003 & 0,0261 & 0,009806 & 0,0069497 \\
IC & 36 & 4,2713 & 6,08448 & 4,686128 & 0,4238835 \\
EO & 36 & 0,5931 & 0,9977 & 0,878289 & 0,0975640 \\
IPI & 36 & 1,1105 & 2,2099 & 1,702072 & 0,2696899 \\
Valid N (listwise) & 36 & & & & \\
\hline
\end{tabular}

2. Uji Asumsi Klasik

a. Uji Normalitas

Tabel 2 Uji Normalitas

\begin{tabular}{llr} 
& & Unstanderdied Residual \\
\hline N & & 36 \\
Normal Parameters $^{\text {a.b }}$ & Mean & 0,0000000 \\
Most Extreme & Std. Deviation & 0,00329973 \\
Differences & Absolute & 0,113 \\
& Positive & 0,113 \\
Kolmogorov-Smirnov Z & Negative & $-0,065$ \\
Asymp. Sig. (2-tailed) & & 0,677 \\
\hline
\end{tabular}

Sumber: Hasil Output SPSS 
Berdasarkan Tabel 2, nilai asymp sig. 2 tailed adalah 0,749 > alpha 0,05 sehingga dapat disimpulkan residual data berdistribusi normal.

b. Uji Heteroskedastisitas

Tabel 3 Uji Heteroskedastisitas

\begin{tabular}{|c|c|c|c|c|c|c|}
\hline \multicolumn{2}{|r|}{ Model } & $\begin{array}{l}\text { Unstandardized } \\
\text { Coefficients } \\
\text { B }\end{array}$ & Std. Error & \multirow[t]{2}{*}{$\begin{array}{c}\text { Standardized } \\
\text { Coefficient } \\
\text { Beta } \\
\end{array}$} & $\mathrm{T}$ & Sig. \\
\hline 1 & Constant & 0,010 & 0,006 & & 1,720 & 0,095 \\
\hline & IC & $-0,001$ & 0,001 & $-0,227$ & $-1,411$ & 0,168 \\
\hline & $\mathrm{EO}$ & $-0,005$ & 0,004 & $-0,230$ & $-1,396$ & 0,172 \\
\hline & IPI & 0,002 & 0,001 & 0,212 & 1,302 & 0,202 \\
\hline
\end{tabular}

Sumber: Hasil Output SPSS

Berdasarkan Tabel 3, dapat diketahui bahwa nilai signifikansi dari variabel IC, Efisiensi Operasional, dan IPI adalah sebesar 0,168; 0,172; dan 0,202 secara berturut-turut. Nilai signifikansi dari seluruh variabel tersebut adalah lebih dari 0,05 sehingga dapat disimpulkan bahwa tidak terjadi heteroskedastisitas.

c. Uji Autokorelasi

Tabel 4 Uji Autokorelasi

\begin{tabular}{cccccc}
\hline Model & R & R Square & Adjusted R Square & $\begin{array}{l}\text { Std. Error of the } \\
\text { Estimate }\end{array}$ & $\begin{array}{l}\text { Durbin- } \\
\text { Watson }\end{array}$ \\
\hline 1 & 0,880 & 0,775 & 0,753 & 0,0034509 & 1,247 \\
\hline
\end{tabular}

Sumber: Hasil Output SPSS

Nilai Durbin-Watson pada Tabel 4.5 adalah 1,247 dimana nilai dU untuk jumlah data 36 dengan 3 variabel independen adalah 1,6539 dan nilai 4-dU adalah 2,3461, maka hasil pengujian ini belum memenuhi syarat untuk terbebas dari autokorelasi karena nilai $\mathrm{dW}<\mathrm{dU}$. Maka dari itu penulis melakukan upaya pengobatan untuk kasus ini dengan cara melakukan Uji Cochrane Orcutt.

d. Uji Cochrane Orutt

Tabel 5 Uji Cochrane Orcutt

\begin{tabular}{cccccc}
\hline Model & $\mathbf{R}$ & R Square & $\begin{array}{c}\text { Adjusted R } \\
\text { Square }\end{array}$ & $\begin{array}{l}\text { Std. Error of the } \\
\text { Estimate }\end{array}$ & $\begin{array}{c}\text { Durbin- } \\
\text { Watson }\end{array}$ \\
\hline 1 & 0,836 & 0,699 & 0,669 & 0,00313 & 1,748 \\
\hline
\end{tabular}

Sumber: Hasil Output SPSS

Nilai Durbin-Watson yang tersaji dalam Tabel 4.6 menunjukkan angka 1,7480. Nilai dU untuk jumlah data 36 dengan 3 variabel independen adalah 1,6539 dan nilai 4-dU adalah 2,3461. Sehingga persyaratan dU $<\mathrm{dW}<4$-dU sudah terpenuhi karena 1,6539 < 1,7480 < 2,3461 maka dapat disimpulkan bahwa data sudah lolos uji autokoreasi atau tidak terdapat autokorelasi.

e. Uji Multikolinearitas 
Tabel 6 Uji Multikolinearitas

\begin{tabular}{|c|c|c|c|c|c|c|c|}
\hline \multirow[t]{2}{*}{ Model } & \multicolumn{2}{|c|}{$\begin{array}{c}\text { Unstanderdized } \\
\text { Coefficients }\end{array}$} & \multirow{2}{*}{$\begin{array}{c}\text { Standardized } \\
\text { Coefficients } \\
\text { Beta }\end{array}$} & \multirow[t]{2}{*}{$\mathrm{t}$} & \multirow[t]{2}{*}{ Sig. } & \multicolumn{2}{|c|}{ Collinearity Statistics } \\
\hline & B & Std. Error & & & & Tolerance & VIF \\
\hline (Constant) & 0,056 & 0,009 & & 6,036 & 0,000 & & \\
\hline IC & $-0,001$ & 0,001 & $-0,067$ & $-0,785$ & 0,438 & 0,971 & 1,030 \\
\hline $\mathrm{EO}$ & $-0,057$ & 0,006 & $-0,798$ & $-9,148$ & 0,000 & 0,926 & 1,080 \\
\hline IPI & 0,005 & 0,002 & 0,204 & 2,367 & 0,024 & 0,950 & 1,053 \\
\hline
\end{tabular}

Sumber: Hasil Output SPSS

Berdasarkan Tabel 6, dapat diketahui bahwa nilai tolerance untuk variabel intellectual capital, efisiensi operasional, dan islamicity performance index secara berturut-turut adalah 0,971; 0,926; dan 0,950. Nilai tolerance seluruh variabel tersebut lebih besar dari 0,1. Sedangkan nilai VIF untuk variabel intellectual capital, efisiensi operasional, dan islamicity performance index secara berturut-turut adalah 1,030; 1,080; dan 1,053. Nilai VIF untuk seluruh variabel adalah lebih kecil dari 10,0. Maka dapat disimpulkan bahwa tidak terjadi multikolinearitas.

\section{Uji Hipotesis}

a. Uji Koefisien Determinasi (R2)

Tabel 7 Uji Koefisien Determinasi (R2)

\begin{tabular}{ccccc}
\hline Model & R & R Square & Adjusted R Square & Std. Error of the Estimate \\
\hline 1 & 0,880 & 0,775 & 0,753 & 0,0034509 \\
\hline
\end{tabular}

Sumber: Hasil Output SPSS

Berdasarkan Tabel 7, dapat diketahui bahwa nilai adjusted $\mathrm{R}$ square adalah 0,753 yang artinya seluruh variabel independen dalam penelitian ini mampu menjelaskan $75,3 \%$ variabel dependen, sedangkan sisanya dijelaskan oleh variabel lain diluar penelitian ini.

\section{b. Uji Nilai F}

Tabel 8 Uji Nilai F

\begin{tabular}{cccccc}
\hline Model & Sum f Squares & Df & Mean Square & F & Sig. \\
\hline Regression & 0,001 & 3 & 0,000 & 23,947 & 0,000 \\
Residual & 0,000 & 31 & 0,000 & & \\
Total & 0,001 & 34 & & & \\
\hline
\end{tabular}

Sumber: Hasil Output SPSS

Hasil olah data pada Tabel 8 menunjukkan bahwa nilai signifikansi untuk uji nilai $\mathrm{F}$ adalah $0,000<$ alpha 0,05 maka dapat disimpulkan bahwa seluruh variabel independen dalam penelitian ini berpengaruh terhadap variabel dependen secara simultan.

c. Uji Nilai t

Tabel 9 Uji Nilai t

\begin{tabular}{|c|c|c|c|c|c|}
\hline \multirow[t]{2}{*}{ Model } & \multicolumn{2}{|c|}{ Unstanderdized Coefficients } & \multirow{2}{*}{$\begin{array}{c}\text { Standardized } \\
\text { Coefficients } \\
\text { Beta }\end{array}$} & \multirow[t]{2}{*}{$\mathrm{t}$} & \multirow[t]{2}{*}{ Sig. } \\
\hline & $\mathrm{B}$ & Std. Error & & & \\
\hline (Constant) & 0,056 & 0,009 & & 6,036 & 0,000 \\
\hline $\mathrm{IC}$ & $-(0,001$ & 0,001 & $-0,067$ & $-0,785$ & 0,438 \\
\hline $\mathrm{EO}$ & $-(0,057$ & 0,006 & $-0,798$ & $-9,148$ & 0,000 \\
\hline IPI & 0,005 & 0,002 & 0,204 & 2,367 & 0,024 \\
\hline
\end{tabular}

Sumber: Hasil Output SPSS 
Berdasarkan hasil uji nilai t yang disajikan dalam Tabel 9, dapat dilihat bahwa variabel intellectual capital memiliki tingkat signifikansi 0,438 > alpha 0,05 dengan arah koefisien negatif. Sehingga dapat disimpulkan bahwa variabel intellectual capital tidak berpengaruh positif terhadap profitabilitas. Sehingga H1 yang berbunyi intellectual capital berpengaruh positif terhadap profitabilitas ditolak.

Untuk variabel efisiensi operasional, nilai t adalah sebesar -9,148 dengan arah koefisien negatif dan tingkat signifikansi 0,000. Tingkat signifikansi $0,000>$ alpha 0,05 dengan arah koefisien negatif menunjukkan bahwa efisiensi operasional berpengaruh terhadap profitabilitas. Dengan demikian dapat disimpulkan bahwa $\mathrm{H} 2$ diterima.

Variabel islamicity performance index memiliki nilai t sebesar 2,367 dengan arah koefisien positif dan tingkat signifikansi 0,024. Tingkat signifikansi 0,024< alpha 0,05 dengan arah koefisien positif menunjukkan bahwa islamicity performance index berpengaruh terhadap profitabilitas. Dengan demikian, maka $\mathrm{H} 3$ yang berbunyi islamicity performance index berpengaruh positif terhadap profitabilitas diterima.

Koefisien regresi untuk variabel intellectual capital, efisiensi operasional, dan islamicity performace index secara berturut-turut adalah -0,001; -0,057; dan 0,005. Sedangkan nilai konstantanya adalah 0,056 . Sehingga diperoleh persamaan regresi sebagai berikut:

$$
\mathbf{P}=0,056-0,001 \mathrm{IC}-0,057 \mathrm{EO}+0,005 \mathrm{IPI}+\mathrm{e}
$$

Adapun hasil pengujian terhadap hipotesis yang terdapat dalam penelitian ini adalah sebagai berikut:

(1) Pengujian Hipotesis Satu (H1)

Nilai signifikansi pada uji t pada variabel intellectual capital menunjukkan angka 0,438 dimana angka tersebut adalah lebih besar dari alpha 0,05. Sehingga dapat disimpulkan bahwa intellectual capital tidak berpengaruh terhadap profitabilitas atau hipotesis satu ditolak. Hal ini dapat disebabkan oleh tingginya gaji dan tunjangan yang diberikan kepada karyawan tetapi tidak diiringi dengan training atau pelatihan, sehingga value added yang dihasilkan oleh karyawan tidak dapat maksimal.

\section{(2) Pengujian Hipotesis Dua (H2)}

Tingkat signifikansi variabel efisiensi operasional sebesar $0,000<$ alpha 0,05 dengan arah koefisien negatif. Dari hasil analisis tersebut, dapat disimpulkan bahwa rendahnya tingkat efisiensi operasional berpengaruh negatif terhadap profitabilitas atau hipotesis dua diterima. Semakin tinggi nilai BOPO maka dapat disimpulkan bahwa semakin rendah efisiensi operasional dari perusahaan tersebut. Sehingga apabila kita kaitkan dengan profitabilitas maka semakin tinggi peringkat rendahnya efisiensi operasional suatu perusahaan maka profitabilitas yang sanggup dihasilkan perusahaan tersebut akan semakin kecil.

\section{(3) Pengujian Hipotesis Tiga (H3)}

Tingkat signifikansi variabel islamicity performance index sebesar $0,024<$ alpha 0,05 dengan arah koefisien positif. Dari hasil analisis tersebut, dapat disimpulkan bahwa islamicity performance index berpengaruh positif terhadap profitabilitas atau hipotesis tiga diterima.

Ketaatan pada syariah Islam ini menjadi salah satu keunggulan kompetitif lembaga islam seperti bank syariah. Keunggulan karena tingginya tingkat ketaatan bank syariah terhadap syariat islam dapat meningkatkan kepercayaan masyarakat untuk menggunakan produk perbankan syariah sehingga meningkatkan profitabilitas bank syariah. 


\section{KESIMPULAN}

Berdasarkan hasil analisis data yang dilakukan oleh penulis, dapat ditarik kesimpulan bahwa Intellectual Capital Tidak Berpengaruh terhadap Profitabilitas. Rendahnya Tingkat Efisiensi Operasional Berpengaruh Negatif terhadap Profitabilitas. Islamicity Performance Index Berpengaruh Positif terhadap Profitabilitas.

\section{DAFTAR PUSTAKA}

Andraeny, D., \& Putri, D. D. (2017). Islamicity Performance Index in Indonesian Islamic Banks. Shirkah Journal of Economic and Bussiness, II (3), 345.

Andriana, R., Fauziah, E. N., \& Bayuni, M. E. (2017). Pelaksanaan dan Pengungkapan Corporate Social Responsibility Perbankan Syariah dalam Perspektif Sharia Enterprise Theory. Jurnal Keuangan dan Perbankan Syariah, III (2), 513.

Awwalin, D. P. (2015). Peluang, Tantangan, dan Prospek Perbankan Syariah Indonesia dalam Menghadapi Persaingan Masyarakat Ekonomi Asean (Mea) 2015.Jurnal Akuntansi UNESA, III (2), 7 .

Barney, J. B. (1991). Firm Resources and Sustained Competitive Advantage. Journal of Management, XVII (1), 99-120.

Ciptaningsih, T. (2013). Uji Pengaruh Modal Intelektual terhadap Kinerja Keuangan BUMN yang Go Public di Indonesia. Jurnal Manajemen Teknologi, XII (3), 342.

Dewanta, P., Hamidah, H., \& Ahmad, G. N. (2016). The Effect of Intellectual Capital and Islamicity Performance Index to the Performance of Islamic Bank in Indonesia 2010-2014 Periods. Jurnal Riset Manajemen Sains Indonesia, VII (2), 275.

Fadjar, A., Esti, H., \& Prihatini, T. (2017). Analisis Faktor Internal dan Eksternal Bank yang Memengaruhi Profitabilitas Bank Umum di Indonesia. Journal of Management and Bussiness Review, I (1), 66.

Ghosh, S., \& Mondal, A. (2012). Indian Software and Pharamaceutical Sector IC and Financial Performances. Journal of Intellectual Capital, X (3), 369-388.

Ghozali, I. (2011). Aplikasi Analisis Multivariate dengan Program IBM SPSS 19, Edisi 5, Cetakan 5, Badan Penerbit Universitas Diponegoro, Semarang.

Hakiim, N., \& Rafsanjani, H. (2016). Pengaruh Internal Capital Adequacy Ratio, Financing to Deposit Ratio, dan Biaya Operasional per Pendapatan Operasional dalam Peningkatan Profitablitas Industri Bank Syariah di Indonesia. Jurnal Perbankan Syariah, I (1), 64-72.

Hameed, S., dkk. (2004). Alternative Disclosure dan Performance for Islamic Bank's, Proceeding of The Second Conference on Administrative Science: Meeting the Challenges of The Globalization Age. Dahran, Saud Arabia.

Harianto, S. (2017). Rasio Keuangan dan Pengaruhnya Terhadap Profitabilitas pada BPR Syariah di Indonesia. Jurnal Bisnis dan Manajemen, XII (1), 47.

Hasan, R., Mohammad, N., \& Alam, M. F. (2017). Impact of Intellectual Capital on ProfitabilityConventional vs Islamic Banks. Journal of Accounting, Finance, and Auditing Studies, III (3), 77.

Otoritas Jasa Keuangan. (2017). Statistik Perbankan Syariah Hingga Desember 2017, www.ojk.go.id. Diakses 1 Oktober 2018 pukul 16.00 WIB.

Ousama, A. A., \& Fatima, A. H. (2015). Intellectual Capital and Islamic Performances of Islamic Banks. Journal Learning and Intellectual Capital, II (1), 11.

Ozkan, N., Cakan, S., \& Kayacan, M. (2017). Intellectual Capital and Financial Performance: A Study of Turkish Banking Sector. Borsa Istanbul Review, XVII (3), 195.

Pal, K., \& Soriya, S. (2012). IC Performances of Indian Pharmaceutical and Textile Industry. Journal of Intelletual Capital, XIII (1), 120-137. 
Parawouw, M. A. (2014). The Application of CAMEL Model on Banks Listed on Indonesia Stock Exchange Period 2008-2010. International Bussiness Administration Journal University of Sam Ratulangi Manado, II (1), 124-233.

Prasetyo, D. A. \& Darmayanti, N. P. A. (2015). Pengaruh Risiko Kredit, Likuiditas, Kecukupan Modal, dan Efisiensi Operasional Terhadap Profitabilitas pada PT BPD Bali. E-Journal Manajemen UNUD, IV (9), 2611-2612.

Pulic, A. (1998). Measuring the Performance of Intellectual Potential in Knowledge Economy. $2^{d}$ McMaster World Congress on Measuring and Managing Intellectual Capital.

Rosafitri, C. (2017). Interaksi Good Corporate Governance, Corporate Social Responsibility, Intellectual Capital, dan Pengaruhya Terhadap Kinerja Keuangan Perusahaan. Journal of Accounting Science, I (1), 17-18.

Sari, K. I., \& Gunawan, B. (2011). Intellectual Capital On the Financial Performance and Company Growth. Jurnal Analisis Bisnis Ekonomi, IX (1), 8.

Ulum, I. (2013). Model Pengukuran Kinerja Intellectual Capital dengan iB-VAIC di Perbankan Syariah”, INFERENSI Jurnal Penelitian Sosial Keagamaan, VII (1), 198-202.

Umami, R. I. (2017). Pengaruh Intellectual Capital Terhadap Finnancial Performances Perusahaan: Perbandingan Antara Bank Syariah dan Bank Konvensional di Indonesia (Periode 2012-2016). Skripsi, Universitas Islam Negeri Sunan Kalijaga Yogyakarta, 125.

Wibowo, S. E., \& Syaichu, M. (2013). Analisis Pengaruh Suku Bunga, Inflasi, CAR, BOPO, dan NPF Terhadap Profitabilitas Bank Syariah. Diponegoro Journal of Management, II (2), 19. 